\title{
A systematic review and meta-analysis on the efficacy of statins in the treatment of atherosclerosis
}

\author{
Jianpu Jia ${ }^{1}$, Leguo Zhang ${ }^{1}$, Lixuan Wang ${ }^{1}$, Chunxue $\mathrm{Ji}^{1}$, Ruixue Xia ${ }^{1}$, Yan Yang ${ }^{2}$ \\ ${ }^{1}$ Department of Neurology, Cangzhou Central Hospital, Cangzhou, China; ${ }^{2}$ Department of Cardiovascular Medicine, Heilongjiang Provincial \\ Hospital, Harbin, China \\ Contributions: (I) Conception and design: J Jia, Y Yang; (II) Administrative support: L Zhang, L Wang; (III) Provision of study materials or patients: \\ J Jia, L Zhang, L Wang, C Ji; (IV) Collection and assembly of data: All authors; (V) Data analysis and interpretation: J Jia, C Ji, R Xia, Y Yang; \\ (VI) Manuscript writing: All authors; (VII) Final approval of manuscript: All authors. \\ Correspondence to: Yan Yang. Department of Cardiovascular Medicine, Heilongiiang Provincial Hospital, 82 Zhongshan Road, Xiangfang District, \\ Harbin 150001, China. Email: yang13633615691@163.com.
}

\begin{abstract}
Background: It was a meta-analysis on the efficacy of statins in the treatment of atherosclerosis.
Methods: The PubMed, Medline, Embase, Web of Sciences, and other Chinese and English databases were used to retrieve literature on randomized controlled trials (RCTs) of statins in the treatment of atherosclerosis, published from January 2000 to January 2021. The Cochrane Handbook for Systematic Reviews of Intervention 5.0.2 was used to conduct bias risk assessment, and Review Manager 5.3 software (RevMan) was used for meta-analysis.
\end{abstract}

Results: A total of 12 articles with 1,180 participants were included in the meta-analysis. In the observation group, the plaque area [mean difference $(\mathrm{MD})=-1.21 ; 95 \%$ confidence interval $(\mathrm{CI}):-2.03$ to $-0.38 ; \mathrm{Z}=2.87$; $\mathrm{P}=0.004]$, total cholesterol (TC) level ( $\mathrm{MD}=-0.72 ; 95 \% \mathrm{CI}:-1.01$ to $-0.43 ; \mathrm{Z}=4.83 ; \mathrm{P}<0.00001$ ), triglyceride (TG) level ( $M D=-0.43 ; 95 \% \mathrm{CI}:-0.76$ to $-0.09 ; \mathrm{Z}=2.51 ; \mathrm{P}=0.01)$, and the low-density lipoprotein (LDL-C) level $(\mathrm{MD}=-0.79 ; 95 \% \mathrm{CI}:-1.41$ to $-0.18 ; \mathrm{Z}=2.54 ; \mathrm{P}=0.01)$ were lower, while the clinical effective rate ( $M D=3.64 ; 95 \%$ CI: 1.39 to $9.53 ; Z=2.64 ; P=0.008$ ) was higher, and the difference was notable. No notable difference was noted in intra-media thickness (IMT) ( $M D=-0.41 ; 95 \% \mathrm{CI}:-0.88$ to $-0.06 ; \mathrm{Z}=1.7 ; \mathrm{P}=0.09$ ), hypersensitive $\mathrm{C}$-reactive protein (hs-CRP) level ( $\mathrm{MD}=-1.61 ; 95 \% \mathrm{CI}:-3.59$ to $0.37 ; \mathrm{Z}=1.7 ; \mathrm{P}=0.09$ ), and high-density lipoprotein (HDL-C) level ( $\mathrm{MD}=0.14 ; 95 \% \mathrm{CI}:-0.02$ to $0.30 ; \mathrm{Z}=2.54 ; \mathrm{P}=0.09$ ) between the 2 groups.

Discussion: The use of statins in the treatment of atherosclerosis can reduce the levels of TC, TG, and LDL-C, mitigate clinical symptoms, and reduce blood lipids with good efficacy.

Keywords: Statins; atherosclerosis; blood lipids; meta-analysis

Submitted Apr 22, 2021. Accepted for publication Jun 17, 2021.

doi: 10.21037/apm-21-1243

View this article at: https://dx.doi.org/10.21037/apm-21-1243

\section{Introduction}

The main cause of atherosclerosis is lipid metabolism disorder, which then leads to accumulation of lipids and complex carbohydrates in the intima, causing hemorrhage and thrombosis, followed by fibrous tissue proliferation and calcium deposition, accompanied by gradual degeneration and calcification of the arterial middle layer, and finally resulting in thickening and hardening of the arterial wall and narrowing of the vascular lumen (1). The disease often involves the great and middle muscular arteries, and when it develops to block the arterial lumen, the tissue or organ supplied by the artery will be ischemic or necrotic. Because the lipids that accumulate in the arterial intima are yellowish, it is called atherosclerosis (2). It is the main cause of cerebral infarction and peripheral vascular diseases. 
Clinical manifestations of atherosclerosis depend on the degree of ischemia of the involved organs, and organ failure may occur in severe cases (3-5).

The main treatment protocols are to lower lipids and widen blood vessels, together with anticoagulant therapy (6). Research in the field of biomedicine has found that statins demonstrate good effects on lowering blood lipids and improving vascular endothelium. Lowering blood lipids mainly involves reducing cholesterol in serum, liver, and aorta, and lowering very low-density lipoprotein cholesterol (VLDL-C) and LDL-C, which can effectively prevent coronary heart disease and delay atherosclerosis (7-9). However, as few meta-analyses have been conducted on the effects of statins in the treatment of atherosclerosis, and there have been limitations in the existing studies such as small sample size and different research focuses, it is impossible to effectively judge the actual treatment effects of statins on atherosclerosis (10). In the study, RCTs involving statins and atherosclerosis were recruited to investigate the efficacy of statins, and meta-analysis was conducted for a systematic analysis.

We present the following article in accordance with the PRISMA reporting checklist (available at https://dx.doi. org/10.21037/apm-21-1243).

\section{Methods}

\section{Literature retrieval}

With "atherosclerosis" AND "clinical treatment" OR "atherosclerosis" AND "statins" as the subject terms, relevant literature was retrieved using Chinese and English databases such as PubMed, Medline, Embase, Web of Sciences, Chinese Biolomedical Literature, Wanfang Chinese Biomedical Association Digital Journals, Wanfang Digital Journals Full-text Database, and Weipu Chinese Sci-tech Journals Full-text Database.

\section{Inclusion and exclusion criteria}

Inclusion criteria: (I) the research participants were atherosclerotic patients who met the diagnostic criteria of the World Health Organization (WHO) or the American Diabetes Association (ADA) or the Clinical Research Guidelines for New Chinese Medicines; (II) the age of participants was 45-88 years old; (III) original research report of randomized design of different groups; (IV) literature of statins intervention; (V) literature containing indexes of blood lipid levels, plaque area, and adverse reactions; (VI) literature in either Chinese or English language.

The exclusion criteria were as follows: (I) patients with diabetes, liver and kidney dysfunction, heart failure, and other co-morbidities; (II) literature with special populations such as pregnant women and children as participants; (III) literature using other intervention methods; (IV) nonoriginal research reports, including reviews, individual case reports, meta-analyses, and summary of treatment experience; (V) literature of pharmacokinetic testing; (VI) animal experiment literature; (VII) literature with no control group set, poor balance between groups, and no comparability between groups; (VIII) literature with incomplete information.

\section{Literature screening}

Literature screening was performed by 2 assessors independently. After literature retrieval, the titles were input into NodeExpress 3.2 first to establish a literature database, with duplicates removed subsequently. After the preliminary screening, the 2 assessors read the titles and abstracts to eliminate any literature that obviously did not meet the inclusion criteria, and then carefully read the full text. In the case of disagreement, a consensus was reached through disussion or under the discretion of a third person.

Certain information of the included literature was extracted such as the first author, year of onset, number of samples, age of participants, intervention measures, and outcome indexes.

\section{Data extraction}

The 2 assessors independently used the self-developed data extraction table to extract data, which was then crosschecked after the extraction. The information extracted included: (I) publication information; (II) baseline data; (III) intervention measures and control measures; (IV) outcome indexes: clinical treatment effective rate, total cholesterol (TC), triglyceride (TG), high-density lipoprotein (HDL-C), low-density lipoprotein (LDL-C), intra-media thickness (IMT), hypersensitive C-reactive protein (hs-CRP), and so on.

\section{Literature bias risk assessment}

Two assessors independently performed bias risk 


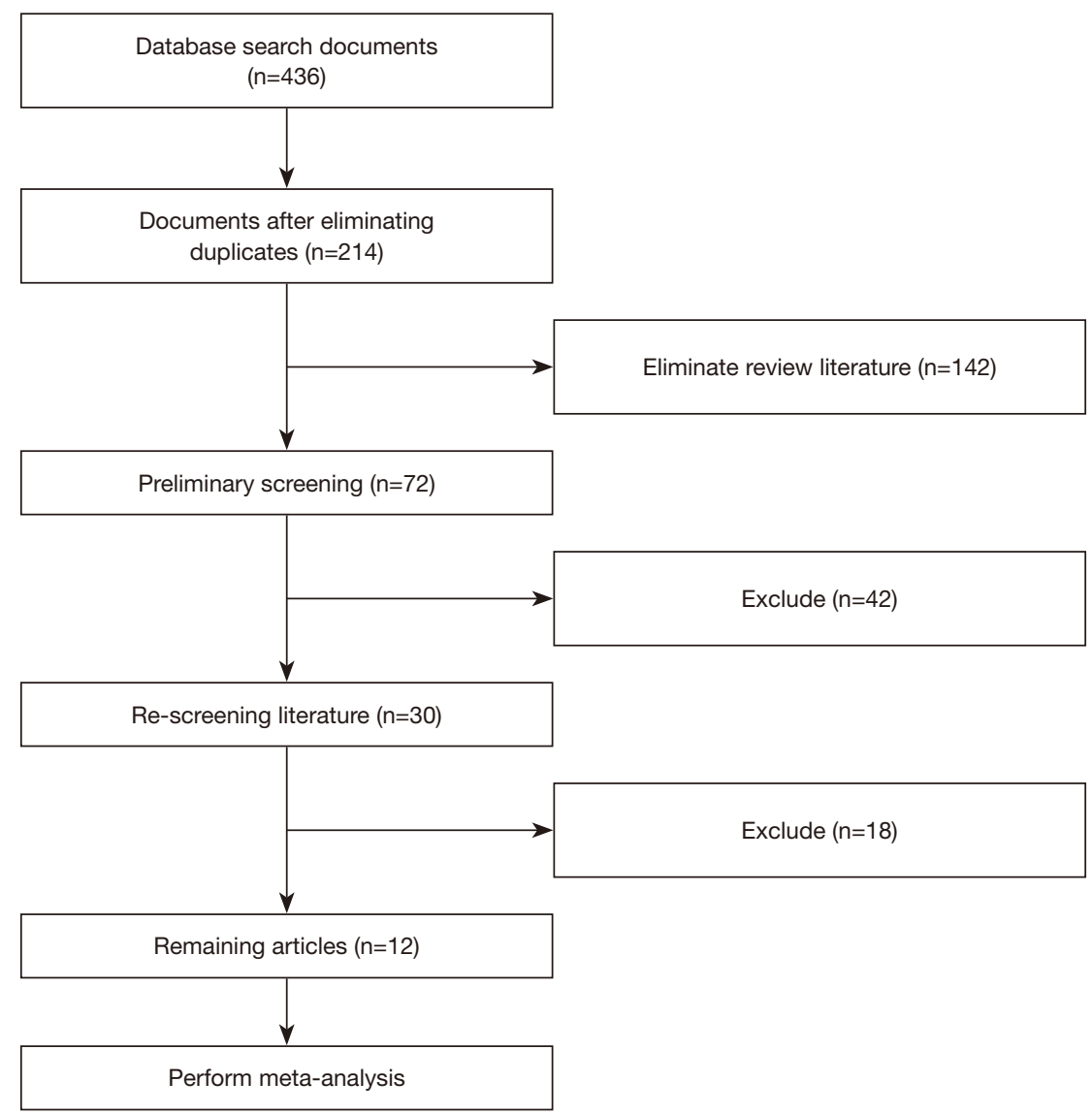

Figure 1 The retrieval process of included studies.

assessment. The assessment criteria included selection bias, implementation bias, measurement bias, follow-up bias, and other biases. Specifically, the criteria included whether it was a random sequence, whether it adopted the allocation concealment, whether participants were blinded, whether the outcome assessor was blinded, whether the data was complete, whether there was selective reporting, and whether there were other biases. Any inconsistencies were resolved by discussion or inviting another one for arbitration.

\section{Statistical methods}

The bias analysis tool in Cochrane Handbook for Systematic Reviews of Interventions 5.1.0 was used to assess the bias risk. The software Stata12.0 was used to process the data of included literature, and the RevMan 5.3 was used for meta-analysis. The combined effect size test adopted $\mathrm{u}$ test and $95 \%$ confidence interval (CI). The u test result was expressed as a $\mathrm{P}$ value, with $\mathrm{P}<0.05$ as the threshold for significance. If heterogeneity sources were found, a fixed effects model (FEM) was used for meta-analysis; if sources of heterogeneity were not found, a random effects model (REM) was used for meta-analysis.

\section{Results}

\section{Literature retrieval and information extraction}

A total of 72 articles were retrieved, and 30 articles remained after the assessors had carefully read the abstract sections. After further reading the full-text according to the inclusion and exclusion criteria, 18 articles were excluded, with 12 RCTs finally retained (11-22) (Figure 1, Table 1).

\section{Bias risk assessment}

(I) Random sequence generation: all 12 reports included used a random grouping method. (II) Allocation 
Table 1 Basic information of included studies

\begin{tabular}{|c|c|c|c|c|c|}
\hline $\begin{array}{l}\text { Year of } \\
\text { publication }\end{array}$ & First author & $\begin{array}{l}\text { Number of samples } \\
(\mathrm{C} / \mathrm{E})\end{array}$ & Control group & Observation group & Outcome indexes \\
\hline 2011 & Liu ZX & $130 / 130$ & Non statin & Atorvastatin & IMT \\
\hline 2012 & Cao YJ & $30 / 30$ & Non statins & Simvastatin & TC, TG, LDL-C, HDL-C, effective rate \\
\hline 2010 & Wang ML & $35 / 35$ & Psychotherapeutics & Pravastatin & $\begin{array}{l}\mathrm{TC}, \mathrm{TG}, \mathrm{LDL}-\mathrm{C} \text {, hs-CRP, effective rate, } \\
\text { plaque area }\end{array}$ \\
\hline 2012 & Liu MH & $40 / 40$ & Non statins & Atorvastatin & TC, TG, LDL-C, HDL-C, effective rate \\
\hline 2014 & Yang QH & $39 / 41$ & Statins & Statins + Betaloc & $\begin{array}{l}\mathrm{TC}, \mathrm{TG}, \mathrm{LDL}-\mathrm{C}, \mathrm{HDL}-\mathrm{C}, \mathrm{hs}-\mathrm{CRP}, \mathrm{IMT} \text {, } \\
\text { plaque area }\end{array}$ \\
\hline 2016 & $\mathrm{Li} X \mathrm{Q}$ & $34 / 34$ & Statins & Statins + Danhong & Effective rate \\
\hline 2017 & Lin DH & $50 / 53$ & Non statins & Statins & TC, TG, LDL-C, HDL-C \\
\hline 2019 & $\mathrm{He} Y J$ & $41 / 45$ & Atorvastatin & Atorvastatin + Exercise & TC, TG, LDL-C, HDL-C, hs-CRP \\
\hline
\end{tabular}

IMT, in intra-media thickness; TC, total cholesterol; TG, triglyceride; LDL-C, low-density lipoprotein; HDL-C, high-density lipoprotein; hsCRP, hypersensitive C-reactive protein.

concealment: all of the 12 articles did not mention whether the blind method was used, suggesting unclear risk. (III) Blindness of participants: none of the 12 documents mentioned whether participants signing an informed consent form, or whether test personnel were blinded, suggesting unclear risk. (IV) Blindness of the outcome assessor: none of the 12 articles reported whether the outcome assessors were blinded, suggesting unclear risk. (V) Data completeness: the outcome data of 12 articles were complete, suggesting low risk. (VI) Selective report: none of the 12 articles were selective reports, suggesting unclear risk. (VII) Other biases: all references suggest unclear risk (Figures 2,3).

\section{Clinical effective rate}

A total of 3 of the 12 articles reported on the effective rate, involving 208 participants, including 104 in the observation group and 104 in the control group. The heterogeneity between two groups was small $\left(\mathrm{I}^{2}=0 \%, \mathrm{P}=0.49\right)$, with FEM used for analysis. It was evident from Figure 4 that the combined effect size was (MD =3.64; $95 \%$ CI: 1.39 to 9.53; $\mathrm{Z}=2.64 ; \mathrm{P}=0.008$ ), which indicated that when statins were used to treat atherosclerosis, the effective rate was higher versus the conventional treatment (Figure 4).

\section{Patch area}

A total of 3 of the 12 articles reported on the plaque area, involving 264 participants, including 133 in the observation group and 131 in the control group. There was a certain degree of heterogeneity between the two groups $\left(\mathrm{I}^{2}=97 \%\right.$, $\mathrm{P}<0.00001$ ), and $\mathrm{REM}$ was used for analysis (Figure 5). The combined effect size was (MD $=-1.21 ; 95 \%$ CI: -2.03 to $-0.38 ; Z=2.87 ; \mathrm{P}=0.004$ ), which indicated that statins demonstrated better effects on alleviating the symptoms of atherosclerosis.

\section{IMT}

A total of 3 of the 12 articles reported on the IMT, involving 454 participants, including 228 in the observation group, and 226 cases in the control group. There was a certain degree of heterogeneity between the two groups $\left(\mathrm{I}^{2}=96 \%, \mathrm{P}<0.00001\right)$, and the REM was used for analysis (Figure 6). The combined effect size was (MD $=-0.41 ; 95 \%$ 


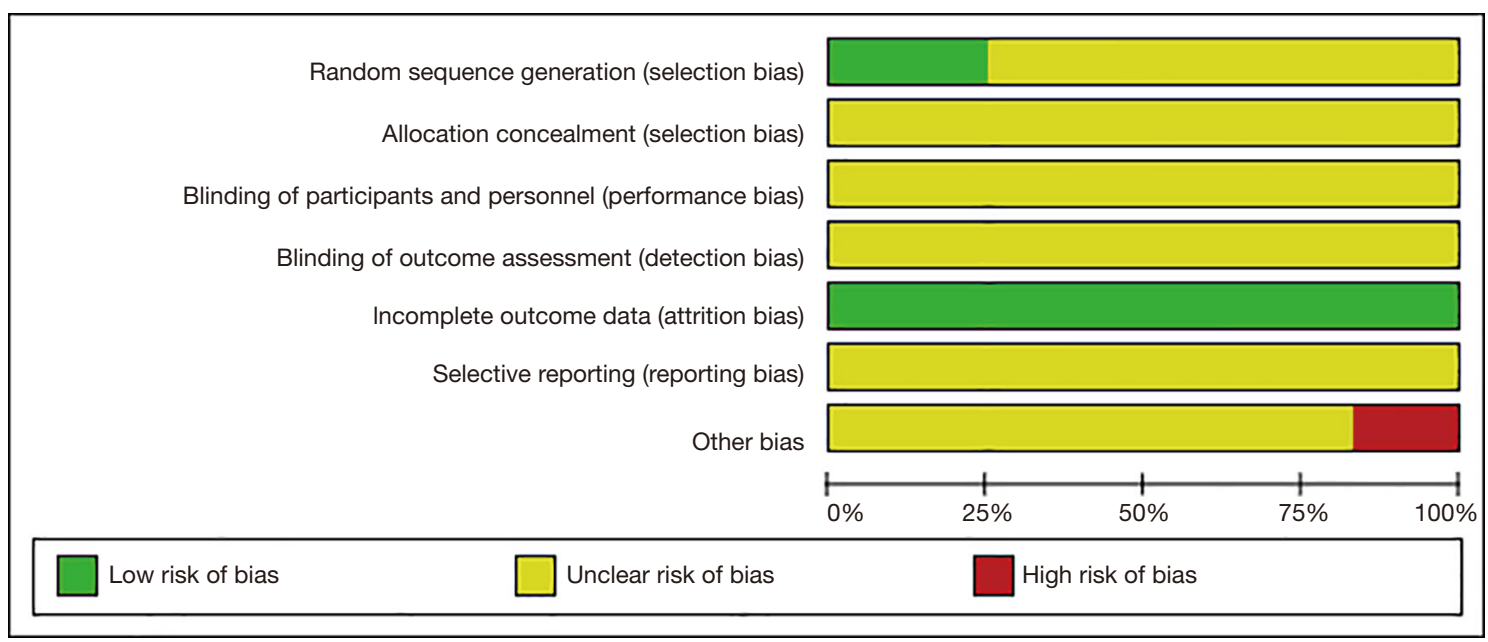

Figure 2 The bias analysis bar chart of included studies.

\begin{tabular}{|c|c|c|c|c|c|c|c|c|c|c|c|c|}
\hline $\begin{array}{l}a \\
\tilde{0} \\
\vec{\omega} \\
\end{array}$ & 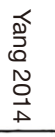 & $\begin{array}{l}\sum_{\Sigma} \\
N \\
O \\
v\end{array}$ & 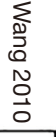 & $\begin{array}{l}3 \\
0 \\
N \\
\stackrel{0}{0} \\
\end{array}$ & $\begin{array}{l}\bar{I} \\
\text { N } \\
\text { O } \\
\stackrel{N}{N}\end{array}$ & $\begin{array}{l}\text { Г. } \\
\text { E. } \\
\text { N } \\
\stackrel{\Xi}{\Xi} \\
\end{array}$ & $\begin{array}{l}\text { I. } \\
\text { N } \\
\text { O } \\
\text { ป }\end{array}$ & 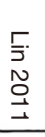 & $\begin{array}{l}\text { ㄷ. } \\
\text { N } \\
\sigma \\
\sigma\end{array}$ & $\begin{array}{l}\frac{T}{D} \\
\tilde{O} \\
O \\
0 \\
\end{array}$ & 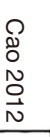 & \\
\hline$\sim$ & $\nu$ & $\omega$ & $\sim$ & + & $\nu$ & $\omega$ & + & $\sim$ & $\nu$ & + & $\sim$ & Random sequence generation (selection bias) \\
\hline$\nu$ & $\nu$ & $\nu$ & $\nu$ & $\omega$ & $\nu$ & $\nu$ & $\nu$ & $\nu$ & $\nu$ & $\nu$ & $\nu$ & Allocation concealment (selection bias) \\
\hline$\sim$ & $\sim$ & $\sim$ & $\sim$ & $\sim$ & $\sim$ & $\sim$ & $\sim$ & $\sim$ & $\sim$ & $\sim$ & $\sim$ & Blinding of participants and personnel (performance bias) \\
\hline$\sim$ & $\nu$ & $\sim$ & $\sim$ & $\sim$ & $\nu$ & $\sim$ & $\sim$ & $\sim$ & $\nu$ & $\sim$ & $\sim$ & Blinding of outcome assessment (detection bias) \\
\hline+ & + & + & + & + & + & + & + & + & + & + & + & Incomplete outcome data (attrition bias) \\
\hline$\sim$ & $\omega$ & $\sim$ & $\sim$ & $\omega$ & $\sim$ & $\sim$ & $\sim$ & $\sim$ & $\omega$ & $\sim$ & $\sim$ & Selective reporting (reporting bias) \\
\hline$\sim$ & $\sim$ & $\sim$ & $\sim$ & $\sim$ & $\sim$ & $\sim$ & 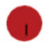 & $\sim$ & $\sim$ & P & $\sim$ & Other bias \\
\hline
\end{tabular}

Figure 3 The bias risk assessment results.

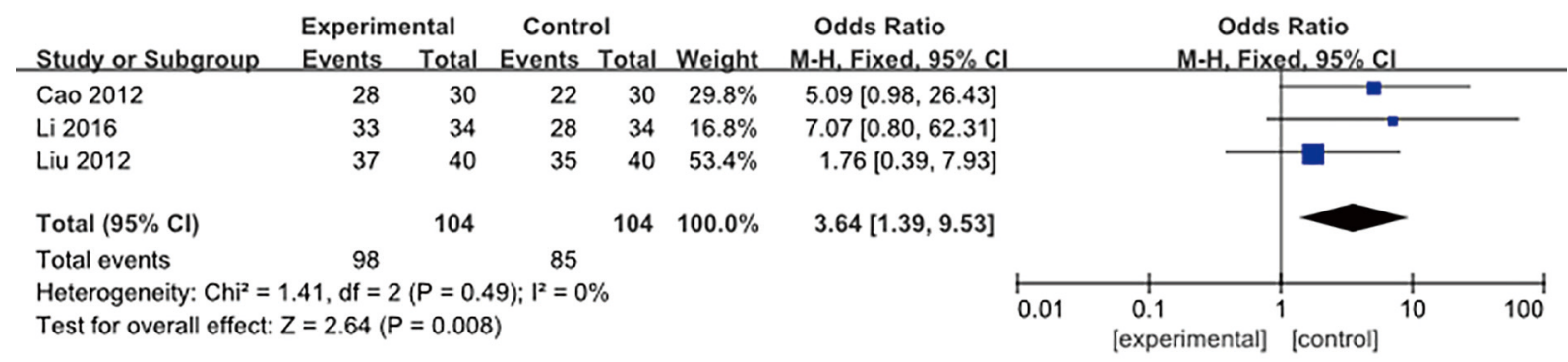

Figure 4 Forest plot of clinical effective rate. 


\begin{tabular}{|c|c|c|c|c|c|c|c|c|c|c|c|}
\hline \multirow[b]{2}{*}{ Study or Subgroup } & \multicolumn{3}{|c|}{ Experimental } & \multicolumn{3}{|c|}{ Control } & & \multirow{2}{*}{$\begin{array}{l}\text { Mean Difference } \\
\text { IV, Random, } 95 \% \text { CI }\end{array}$} & \multirow{2}{*}{\multicolumn{2}{|c|}{$\begin{array}{c}\text { Mean Difference } \\
\text { IV. Random. } 95 \% \mathrm{Cl}\end{array}$}} & \\
\hline & Mean & $\mathrm{SD}$ & Total & Mean & SD & Total & Weight & & & & \\
\hline Lin 2011 & 0.7 & 0.3 & 57 & 1.7 & 0.5 & 57 & $41.1 \%$ & $-1.00[-1.15,-0.85]$ & ] & & \\
\hline Wang 2010 & 17.1 & 3.1 & 35 & 21.1 & 3.2 & 35 & $17.8 \%$ & $-4.00[-5.48,-2.52]$ & & & \\
\hline Yang 2014 & 0.4 & 0.3 & 41 & 0.6 & 0.4 & 39 & $41.1 \%$ & $-0.20[-0.36,-0.04]$ & 단 & & \\
\hline Total $(95 \% \mathrm{Cl})$ & & & 133 & & & 131 & $100.0 \%$ & $-1.21[-2.03,-0.38]$ & & & \\
\hline $\begin{array}{l}\text { Heterogeneity: } \mathrm{Tau}^{2} \\
\text { Test for overall effect }\end{array}$ & $\begin{array}{l}0.42 ; C h \\
Z=2.87\end{array}$ & $\begin{array}{l}=72.3 \\
P=0.0\end{array}$ & $\begin{array}{l}34, \mathrm{df}= \\
004)\end{array}$ & $=2(P<$ & 0.000 & 001); $1^{2}$ & $=97 \%$ & & $\begin{array}{cc}-4 & -2 \\
& \text { [experimental] }\end{array}$ & $\begin{array}{lr}0 & 2 \\
& \end{array}$ & 4 \\
\hline
\end{tabular}

Figure 5 Forest plot of plaque area.

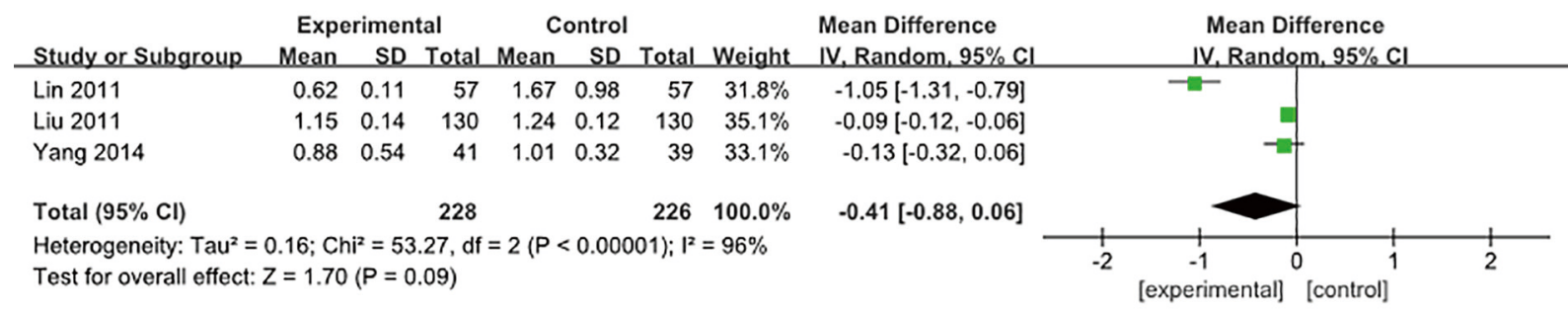

Figure 6 Forest plot of IMT. IMT, intra-media thickness.

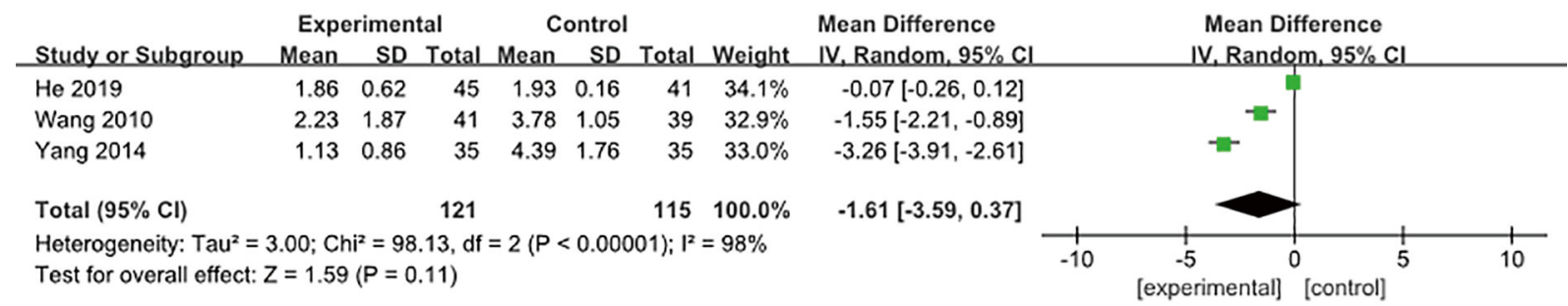

Figure 7 Forest plot of hs-CRP. hs-CRP, hypersensitive C-reactive protein.

CI: -0.88 to $-0.06 ; Z=1.7 ; P=0.09)$, which indicated that there was no notable difference in IMT between the 2 groups after treatment.

\section{bs-CRP}

A total of 3 of the 12 articles reported on hs-CRP, involving a total of 236 participants, including 121 in the observation group, and 115 cases in the control group. There was a certain degree of heterogeneity between the two groups $\left(\mathrm{I}^{2}=98 \%, \mathrm{P}<0.00001\right)$; therefore, $\mathrm{REM}$ was used for analysis (Figure 7). The combined effect size was ( $\mathrm{MD}=-1.61 ; 95 \% \mathrm{CI}:-3.59$ to $0.37 ; \mathrm{Z}=1.7 ; \mathrm{P}=0.09$ ), which showed that there was no notable difference in hs-CRP level between the 2 groups of participants after treatment.

\section{$T C$}

A total of 10 of the 12 articles reported on the TC, involving 858 participants included, including 431 cases in the observation group and 427 cases in the control group. There was a certain degree of heterogeneity between the two groups $\left(\mathrm{I}^{2}=82 \%, \mathrm{P}<0.00001\right)$; therefore, the REM was used for analysis (Figure 8). The combined effect size was ( $M D=-0.72 ; 95 \%$ CI: -1.01 to $-0.43 ; Z=4.83 ; \mathrm{P}<0.00001$ ), which indicated that statins were more effective at reducing TC level.

\section{$T G$}

A total of 9 of the 12 articles reported on the TG, involving 773 participants, including 391 cases in the observation 


\begin{tabular}{|c|c|c|c|c|c|c|c|c|c|c|c|}
\hline \multirow[b]{2}{*}{ Study or Subgroup } & \multicolumn{3}{|c|}{ Experimental } & \multirow{2}{*}{\multicolumn{2}{|c|}{ Control }} & & & Mean Difference & \multirow{2}{*}{\multicolumn{3}{|c|}{$\begin{array}{l}\text { Mean Difference } \\
\text { IV. Random, } 95 \% \mathrm{cl}\end{array}$}} \\
\hline & Mean & SD & Total & & & Total & Weight & IV, Random, $95 \% \mathrm{Cl}$ & & & \\
\hline Cao 2012 & 8.52 & 0.94 & 30 & 9.03 & 0.34 & 30 & $10.7 \%$ & $-0.51[-0.87,-0.15]$ & & & \\
\hline He 2019 & 3.3 & 0.8 & 45 & 4 & 1.4 & 41 & $9.4 \%$ & $-0.70[-1.19,-0.21]$ & & & \\
\hline Lin 2011 & 4.31 & 0.57 & 57 & 4.32 & 0.89 & 57 & $11.5 \%$ & $-0.01[-0.28,0.26]$ & & & \\
\hline Lin 2017 & 4.34 & 0.73 & 53 & 5.38 & 0.45 & 50 & $11.8 \%$ & $-1.04[-1.27,-0.81]$ & & & \\
\hline Liu 2012 & 4.25 & 0.92 & 40 & 4.67 & 0.83 & 40 & $10.5 \%$ & $-0.42[-0.80,-0.04]$ & & & \\
\hline Mo 2018 & 4.44 & 1.26 & 44 & 5.89 & 1.31 & 44 & $8.9 \%$ & $-1.45[-1.99,-0.91]$ & & & \\
\hline Wang 2010 & 5.54 & 1.09 & 35 & 6.09 & 1.08 & 35 & $9.2 \%$ & $-0.55[-1.06,-0.04]$ & & & \\
\hline Wu 2015 & 4.23 & 0.92 & 46 & 5.24 & 0.68 & 46 & $11.0 \%$ & $-1.01[-1.34,-0.68]$ & & & \\
\hline Yang 2014 & 4.88 & 1.56 & 41 & 5.31 & 1.23 & 39 & $8.1 \%$ & $-0.43[-1.04,0.18]$ & & & \\
\hline Yu 2013 & 3.25 & 1.16 & 40 & 4.41 & 1.32 & 40 & $8.8 \%$ & $-1.16[-1.70,-0.62]$ & & & \\
\hline Total $(95 \% \mathrm{Cl})$ & & & 431 & & & 422 & $100.0 \%$ & $-0.72[-1.01,-0.43]$ & & & \\
\hline $\begin{array}{l}\text { Heterogeneity: } \mathrm{Tau}^{2}= \\
\text { Test for overall effect }\end{array}$ & $\begin{array}{l}0.17 ; \mathrm{Ch} \\
z=4.83\end{array}$ & $\begin{array}{l}\mathrm{i}^{2}=50 \\
(\mathrm{P}<0\end{array}$ & $\begin{array}{l}29, \mathrm{df}= \\
00001)\end{array}$ & $=9(P$ & $<00$ & 01); $1^{2}$ & $=82 \%$ & & $\begin{array}{c}-1 \\
\text { [experimental] }\end{array}$ & ${ }_{\text {[control] }}$ & 1 \\
\hline
\end{tabular}

Figure 8 Forest plot of TC. TC, total cholesterol

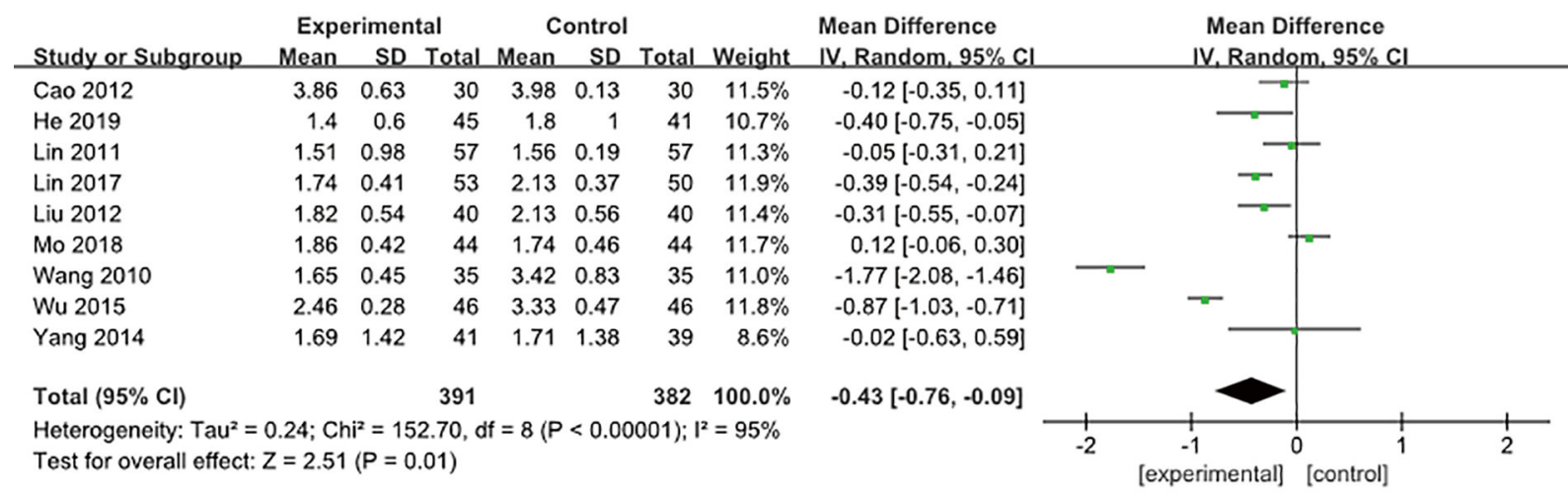

Figure 9 Forest plot of TG. TG, triglyceride.

group and 382 cases in the control group. There was a certain degree of heterogeneity between the two groups $\left(\mathrm{I}^{2}=95 \%, \mathrm{P}<0.00001\right)$; therefore, the REM was used for analysis (Figure 9). The combined effect size was ( $M D=-0.43 ; 95 \% \mathrm{CI}:-0.76$ to $-0.09 ; \mathrm{Z}=2.51 ; \mathrm{P}=0.01$ ), which indicated that statins were more effective in lowering TG levels.

\section{$L D L-C$}

A total of 10 of the 12 articles reported on LDL-C, involving a total of 858 participants, including 431 cases in the observation group and 427 cases in the control group. There was a certain degree of heterogeneity between the two groups $\left(\mathrm{I}^{2}=97 \%, \mathrm{P}<0.00001\right)$; therefore, the REM was used for analysis (Figure 10). The combined effect size was $(\mathrm{MD}=-0.79 ; 95 \% \mathrm{CI}:-1.41$ to $-0.18 ; \mathrm{Z}=2.54 ; \mathrm{P}=0.01)$, which indicated that statins were more effective at lowering
LDL-C levels.

\section{$H D L-C$}

A total of 9 of the 12 articles reported on HDL-C, involving total of 788 participants, including 396 cases in the observation group and 392 cases in the control group. There was a certain degree of heterogeneity between the two groups $\left(\mathrm{I}^{2}=92 \%, \mathrm{P}<0.00001\right)$; therefore, the REM was used for analysis (Figure 11). The combined effect size was ( $\mathrm{MD}=0.14 ; 95 \% \mathrm{CI}:-0.02$ to $0.30 ; \mathrm{Z}=2.54 ; \mathrm{P}=0.09)$, which indicated that there was no notable difference in HDL-C levels of the 2 participant groups after treatment.

\section{Publication bias}

The RevMan 5.3 was used to analyze the publication bias (Figure 12). It was evident that the patient's clinical effective 


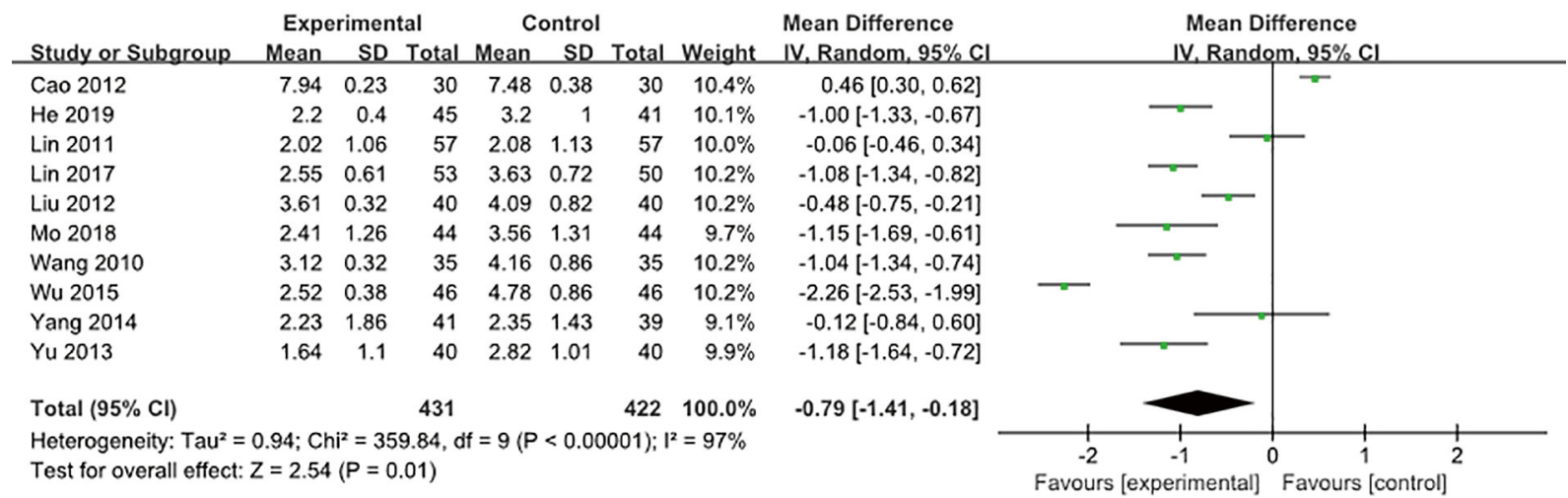

Figure 10 Forest plot of LDL-C. LDL-C, low-density lipoprotein.

\begin{tabular}{|c|c|c|c|c|c|c|c|c|c|c|c|}
\hline \multirow{2}{*}{ Study or Subgroup } & \multicolumn{3}{|c|}{ Experimental } & \multicolumn{2}{|c|}{ Control } & \multirow[b]{2}{*}{ Total } & \multirow[b]{2}{*}{ Weight } & \multirow{2}{*}{$\begin{array}{l}\text { Mean Difference } \\
\text { IV, Random, } 95 \% \mathrm{Cl}\end{array}$} & \multirow{2}{*}{\multicolumn{2}{|c|}{$\begin{array}{c}\text { Mean Difference } \\
\text { IV. Random, } 95 \% \mathrm{Cl}\end{array}$}} & \\
\hline & Mean & SD & Total & Mean & SD & & & & & & \\
\hline Cao 2012 & 0.91 & 0.12 & 30 & 0.89 & 0.5 & 30 & $11.9 \%$ & $0.02[-0.16,0.20]$ & & & \\
\hline $\mathrm{He} 2019$ & 1.16 & 0.23 & 45 & 1.04 & 0.16 & 41 & $13.6 \%$ & $0.12[0.04,0.20]$ & & & \\
\hline Lin 2011 & 1.63 & 0.46 & 57 & 1.63 & 0.79 & 57 & $10.8 \%$ & $0.00[-0.24,0.24]$ & & & \\
\hline Lin 2017 & 1.34 & 0.35 & 53 & 0.95 & 0.31 & 50 & $12.9 \%$ & $0.39[0.26,0.52]$ & & & \\
\hline Liu 2012 & 1.03 & 0.22 & 40 & 1.21 & 0.16 & 40 & $13.5 \%$ & $-0.18[-0.26,-0.10]$ & & & \\
\hline Mo 2018 & 1.97 & 0.43 & 44 & 1.49 & 0.46 & 44 & $11.8 \%$ & $0.48[0.29,0.67]$ & & & \\
\hline Wu 2015 & 1.13 & 0.41 & 46 & 0.85 & 0.32 & 46 & $12.5 \%$ & $0.28[0.13,0.43]$ & & & \\
\hline Yang 2014 & 1.23 & 0.36 & 41 & 1.2 & 0.21 & 39 & $12.9 \%$ & $0.03[-0.10,0.16]$ & & & \\
\hline Yu 2013 & 1.6 & 0.47 & 40 & 1.35 & 0.41 & 0 & & Not estimable & & & \\
\hline Total $(95 \% \mathrm{Cl})$ & & & 396 & & & 347 & $100.0 \%$ & $0.14[-0.02,0.30]$ & & & \\
\hline $\begin{array}{l}\text { Heterogeneity: } \mathrm{Tau}^{2}= \\
\text { Test for overall effect: }\end{array}$ & $\begin{array}{l}0.05 ; \mathrm{Ch} \\
\mathrm{Z}=1.71\end{array}$ & $\begin{array}{l}\mathrm{i}^{2}=86 \\
(P=0\end{array}$ & $\begin{array}{l}.07, \mathrm{df} \\
.09)\end{array}$ & $=7(\mathrm{P}$ & 0.00 & 1); $\left.\right|^{2}=$ & $=92 \%$ & & $\begin{array}{ll}-0.5 & -0.25 \\
\text { [experimental] }\end{array}$ & $\begin{array}{r}0.25 \\
\text { [control] }\end{array}$ & 0.5 \\
\hline
\end{tabular}

Figure 11 Forest plot of HDL-C. HDL-C, high-density lipoprotein.

rate, IMT, TC, and HDL-C levels were basically distributed within the credible interval, indicating small literature bias; the points distribution representing plaque area, hs-CRP, TG, and LDL-C in the funnel chart was scattered, with some points falling outside the credible interval, indicating a certain degree of bias.

\section{Discussion}

Atherosclerosis is one of the main causes of vascular disease and is associated with a high incidence of cerebral infarction and myocardial infarction (23). According to related studies, the mortality rate of acute cerebral infarction caused by atherosclerosis has been increasing annually over recent years. The stability of atherosclerotic plaque is affected by various cellular components, and hyperlipidemia has also been found to be closely related to atherosclerosis $(24,25)$. Therefore, reducing the patient's blood lipid level can effectively control the occurrence and development of atherosclerosis (26). Statins are also known as 3-hydroxy-3 methylglutaryl-coenzyme A (HMG-CoA) reductase inhibitors, which can not only potently reduce TC and LDL levels, but also reduce TG level to a certain extent, and improve HDL level. Consequently, statins are comprehensive lipid-lowering drugs (27). The action mechanism is to competitively inhibit HMG-CoA reductase and block the intracellular mevalonic acid metabolism pathway, reducing intracellular cholesterol synthesis. The number and activity of LDL receptors on the cell membrane surface increases via feedback stimulation, which further clears serum cholesterol. Thus, stains are clinically used in the treatment of atherosclerosis on account of their cholesterol lowering action (28).

This study aimed to systematically evaluate the clinical efficacy of statins in the treatment of atherosclerosis. A total of 12 reports were included, and meta-analysis was applied. 
A

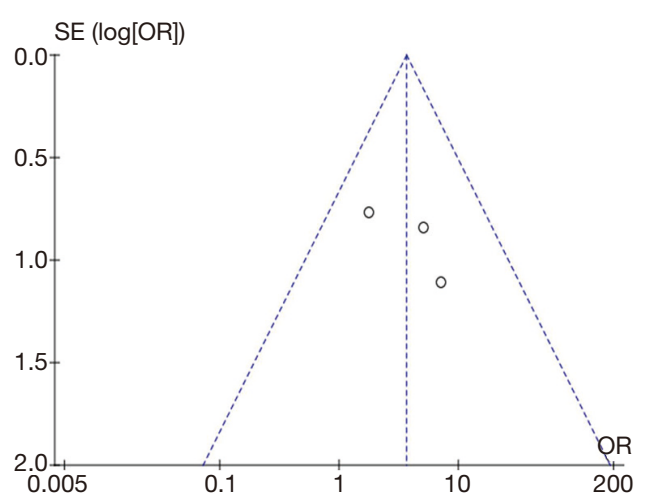

$C_{0.00} \mathrm{SE}(\mathrm{MD})$
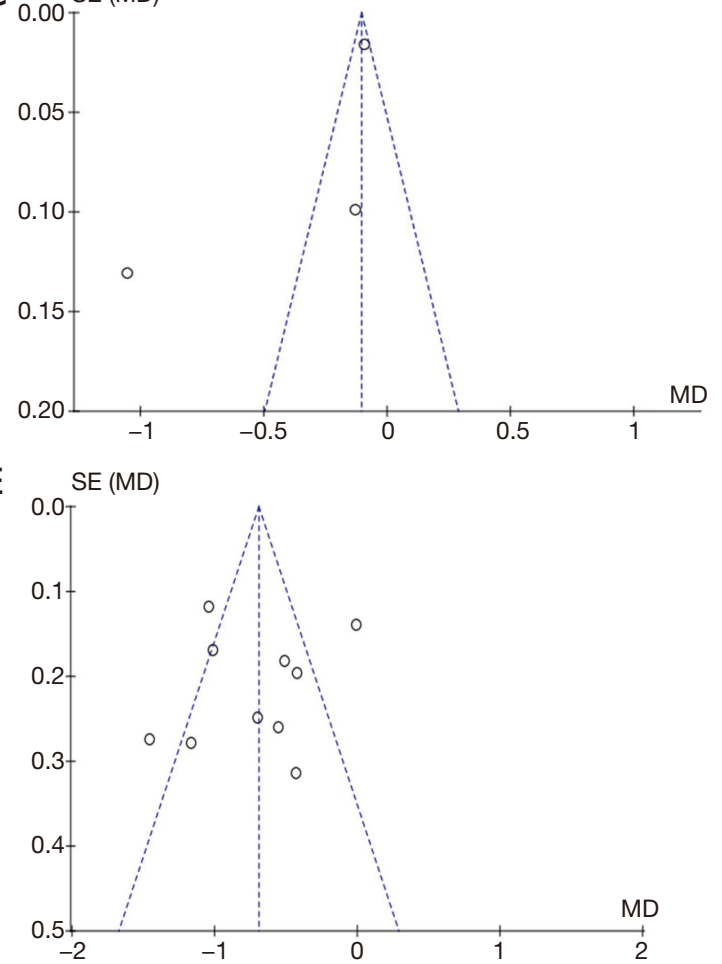

G

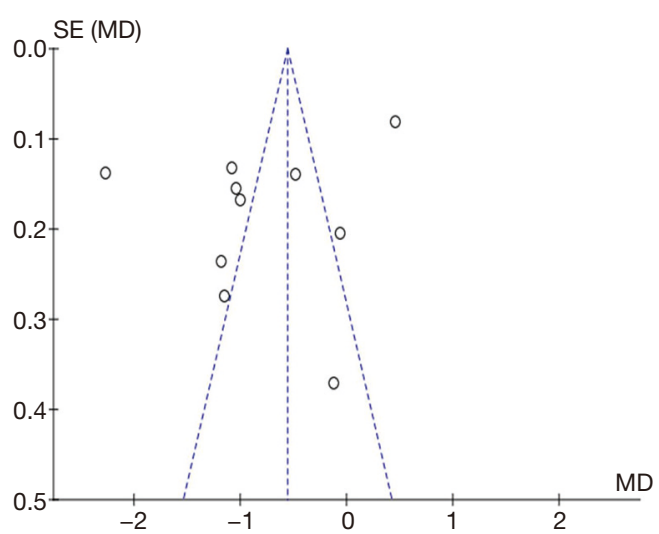

B

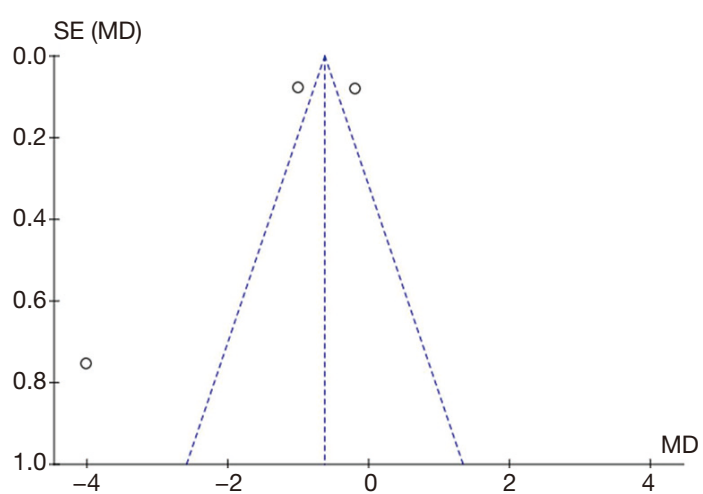

D

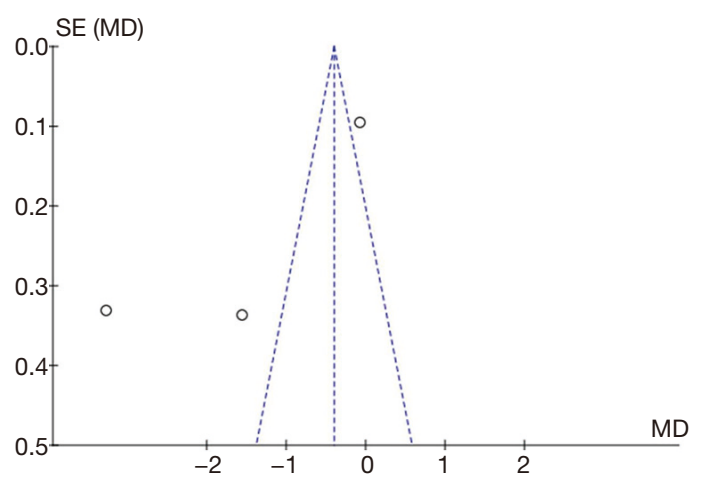

$F_{0.0} \mathrm{SE}(\mathrm{MD})$

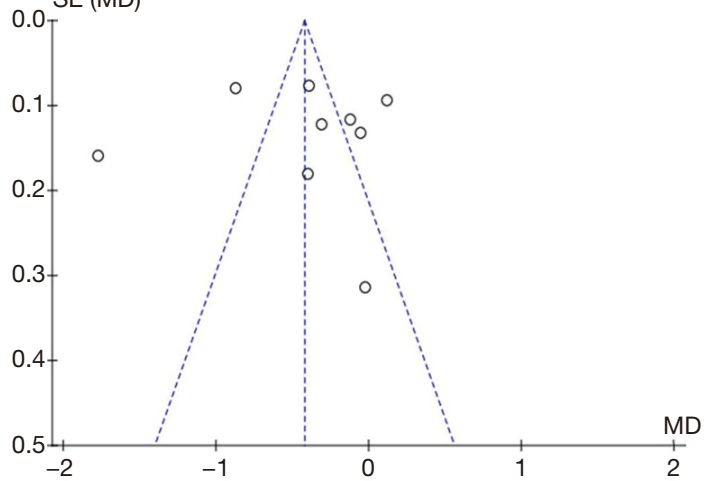

$\mathrm{H}$

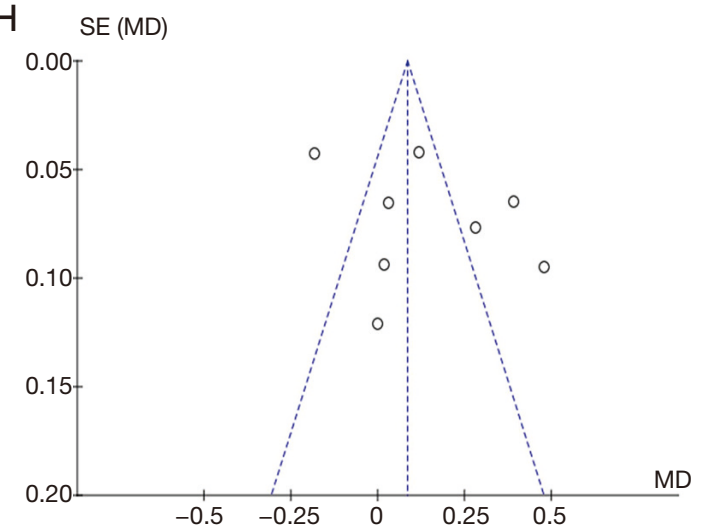

Figure 12 The funnel chart of each index (A) clinical effective rate; (B) plaque area; (C) IMT; (D) hs-CRP; (E) TC; (F) TG; (G) LDL-C; (H) HDL-C. IMT, in intra-media thickness; hs-CRP, hypersensitive C-reactive protein; TC, total cholesterol; TG, triglyceride; LDL-C, lowdensity lipoprotein; HDL-C, high-density lipoprotein. 
It was found that there was no notable difference in IMT, hs-CRP, and HDL-C in participants after treatment, which failed to support that statins can reduce IMT, hs-CRP, and increase HDL-C levels. By comparing the plaque area of the 2 participant groups after treatment, it was found that the plaque area of the observation group was lower than that of the control group, suggesting that the treatment effects of statins were better. Moreover, the levels of TC, TG, and LDL-C in the observation group were lower than those in the control group. This may have been due to the reduction of cholesterol synthesis via the increased number of LDL receptors on the cell membrane surface. After treatment, the clinical effective rate of the observation group was higher than that of the control group, confirming that statins were superior in the treatment of atherosclerosis.

\section{Conclusions}

In conclusion, the use of stains in the treatment of atherosclerosis can effectively mitigate the clinical symptoms of patients and alleviate their discomfort, demonstrating broad application prospects. This research can provide a reference for the clinical treatment of atherosclerosis. However, some limitations should be noted. There was large publication bias in some reports. In addition, some reports contained a small sample size, and the meta-analysis results were not accurate enough. Therefore, in the future, it is necessary to incorporate a larger sample size to verify the efficacy of stains in the treatment of atherosclerosis.

\section{Acknowledgments}

Funding: This study was supported by the Cangzhou Science and Technology Project (131302052).

\section{Footnote}

Reporting Checklist: We present the study in accordance with the PRISMA reporting checklist. available at https://dx.doi. org/10.21037/apm-21-1243

Conflicts of Interest: All authors have completed the ICMJE uniform disclosure form (available at https://dx.doi. org/10.21037/apm-21-1243). The authors have no conflicts of interest to declare.

Ethical Statement: The authors are accountable for all aspects of the work in ensuring that questions related to the accuracy or integrity of any part of the work are appropriately investigated and resolved.

Open Access Statement: This is an Open Access article distributed in accordance with the Creative Commons Attribution-NonCommercial-NoDerivs 4.0 International License (CC BY-NC-ND 4.0), which permits the noncommercial replication and distribution of the article with the strict proviso that no changes or edits are made and the original work is properly cited (including links to both the formal publication through the relevant DOI and the license). See: https://creativecommons.org/licenses/by-nc-nd/4.0/.

\section{References}

1. Herrington W, Lacey B, Sherliker P, et al. Epidemiology of Atherosclerosis and the Potential to Reduce the Global Burden of Atherothrombotic Disease. Circ Res 2016;118:535-46.

2. Poznyak A, Grechko AV, Poggio P, et al. The Diabetes Mellitus-Atherosclerosis Connection: The Role of Lipid and Glucose Metabolism and Chronic Inflammation. Int J Mol Sci 2020;21:1835.

3. Sanchez-Rodriguez E, Egea-Zorrilla A, Plaza-Díaz $\mathrm{J}$, et al. The Gut Microbiota and Its Implication in the Development of Atherosclerosis and Related Cardiovascular Diseases. Nutrients 2020;12:605.

4. Iida M, Harada S, Takebayashi T. Application of Metabolomics to Epidemiological Studies of Atherosclerosis and Cardiovascular Disease. J Atheroscler Thromb 2019;26:747-57.

5. Burke AC, Huff MW. Regression of atherosclerosis: lessons learned from genetically modified mouse models. Curr Opin Lipidol 2018;29:87-94.

6. Staciwa M, Broncel $M$. The biological function and significance of IL-35 in the pathogenesis of atherosclerosis. Pol Merkur Lekarski 2018;44:161-4.

7. Zhu K, Meng Q, Zhang Z, et al. Aryl hydrocarbon receptor pathway: Role, regulation and intervention in atherosclerosis therapy (Review). Mol Med Rep 2019;20:4763-73.

8. Yvan-Charvet L, Cariou B. Poststatin era in atherosclerosis management: lessons from epidemiologic and genetic studies. Curr Opin Lipidol 2018;29:246-58.

9. Santovito D, Weber C. Atherosclerosis revisited from a clinical perspective: still an inflammatory disease? Thromb Haemost 2017;117:231-7.

10. Beita AKV, Whayne TF. The Superior Mesenteric Artery: 
From Syndrome in the Young to Vascular Atherosclerosis in the Old. Cardiovasc Hematol Agents Med Chem 2019;17:74-81.

11. Liu Z, Zhan QF. Curative effect of amlodipine and atorvastatin in treatment of primary hypertension carotid atherosclerotic plaques. China Modern Medicine 2011;30:45-6.

12. Cao YJ. Efficacy observation of simvastatin in treatment of atherosclerotic plaque. China Modern Medicine 2012;2:66-7.

13. Wang M, Huang S. Effect of pravastatin on plasma hs-C-reactive protein in patients with carotid atherosclerosis. Journal of Clinical Internal Medicine 2010;6:394-5.

14. Lin G, Si WM. Clinical effect observation of simvastatin on carotid atherosclerotic plaques. Medical Forums in Basic 2011;20:586-7.

15. Liu MH. Coronary atherosclerotic heart disease and angina pectoris clinical treatment experience. HealthmustReadmagazine 2012:10:48.

16. Yang QH, Zhang R. Effect of Metoprolol Combined with Statin on Carotid Atherosclerosis. Practical Journal of Cardiac Cerebral Pneumal and Vascular Disease 2014;3:34-35,43.

17. Yu QZ. Analysis of Clinical Effect of Statin Drugs in the Treatment of Atherosclerosis. Chinese Journal of Medicinal Guide 2013;6:1014-6.

18. Xu S, Wu QY, Guo G, et al. The effect of lipid regulation with atorvastatin on the blood lipid levels and carotid artery plaques in patients with atherosclerotic cerebral infarction. Chinese Journal of Contemporary Neurology and Neurosurgery 2015;11:904-8.

19. Mo FL. Comparative Study on the Effect of Different Statins in the Treatment of Elderly Patients with Atherosclerosis Acute Cerebral Infarction Complicated

Cite this article as: Jia J, Zhang L, Wang L, Ji C, Xia R, Yang Y. A systematic review and meta-analysis on the efficacy of statins in the treatment of atherosclerosis. Ann Palliat Med 2021;10(6):6793-6803. doi: 10.21037/apm-21-1243 with Hyperlipidemia. Medicine Healthcare Apparatus 2018;5:242-3.

20. Yu QY, Li XQ, Wang H. Research of Clinical Effect of Dan Hong Injection Combined Statin Drugs in Treatment of Coronary Atherosclerosis Heart Disease. Journal of Mathematical Medicine 2016;11:1661-2.

21. Lin DH, Chen MS, Du ZJ, et al. Therapeutic effect of statins on patients with diabetes mellitus complicated atherosclerotic cardiovascular diseases. Chinese Journal of Cardiovascular Rehabilitation Medicine 2017;4:413-6.

22. He YJ, He Y, Wang Y, et al. Effect of atorvastatin combined with brisk walking on coronary atherosclerotic plaques. Shanxi Medical Journal 2019;653-6.

23. Guo FX, Hu YW, Zheng L, et al. Shear Stress in Autophagy and Its Possible Mechanisms in the Process of Atherosclerosis. DNA Cell Biol 2017;36:335-46.

24. Doodnauth SA, Grinstein S, Maxson ME. Constitutive and stimulated macropinocytosis in macrophages: roles in immunity and in the pathogenesis of atherosclerosis. Philos Trans R Soc Lond B Biol Sci 2019;374:20180147.

25. Thomas GS, Wann LS, Allam AH, et al. Why did ancient people have atherosclerosis?: from autopsies to computed tomography to potential causes. Glob Heart 2014;9:229-37.

26. Sage AP, Mallat $Z$. Readapting the adaptive immune response - therapeutic strategies for atherosclerosis. $\mathrm{Br} \mathrm{J}$ Pharmacol 2017;174:3926-39.

27. Durante A, Peretto G, Laricchia A, et al. Role of the renin-angiotensin-aldosterone system in the pathogenesis of atherosclerosis. Curr Pharm Des 2012;18:981-1004.

28. Wilck N, Ludwig A. Targeting the ubiquitin-proteasome system in atherosclerosis: status quo, challenges, and perspectives. Antioxid Redox Signal 2014;21:2344-63.

(English Language Editor: J. Jones) 